\title{
Response of nitric oxide pathway to L-arginine infusion at the altitude of $4,350 \mathrm{~m}$
}

\author{
J-C. Schneider*, I. Blazy\#, M. Déchaux*, D. Rabier", N.P. Mason*, J-P. Richalet*
}

Response of nitric oxide pathway to L-arginine infusion at the altitude of 4,350 m.J-C. Schneider, I. Blazy, M. Déchaux, D. Rabier, N.P. Mason, J-P. Richalet. (C)ERS Journals Ltd 2001.

ABSTRACT: It was hypothesized that hypoxia may inhibit nitric oxide (NO) production by reducing the availability of endothelial NO synthase (NOS III) substrate.

To evaluate the effect of $\mathrm{L}$-arginine on the NO release in high altitude, 11 subjects were infused with $\mathrm{L}$-arginine $\left(0.5 \mathrm{~g} \cdot \mathrm{kg}^{-1}\right)$ during $30 \mathrm{~min}$ in normoxia and after $36 \mathrm{~h}$ at 4,350 $\mathrm{m}$ (hypoxia). The L-citrulline and cyclic guanosine monophosphate (cGMP) concentrations were measured to investigate NO synthesis and guanylyl cyclase activity respectively. L-citrulline concentration, arterial oxygen saturation $\left(\mathrm{Sa}_{\mathrm{a}} \mathrm{O}_{2}\right)$, systemic blood pressure, heart rate and acute mountain sickness (AMS) score were measured at rest and 15,30 and 45 min after starting infusion.

The results showed that baseline $L$-citrulline was lower in hypoxia $(p<0.05)$. L-arginine infusion increased L-citrulline concentration in both conditions. However, in hypoxia L-citrulline concentration remained lower than in normoxia $(\mathbf{p}<\mathbf{0 . 0 5})$. The concentration of cGMP was lower in hypoxia $(\mathrm{p}<0.05)$. In hypoxia, $\mathrm{Sa}_{\mathrm{a}} \mathrm{O}_{2}$ increased from $15 \mathrm{~min}$ after the start of the infusion to $45 \mathrm{~min}(\mathrm{p}<0.05)$. Blood pressure and heart rate were not affected by L-arginine infusion.

Subjects who experienced symptoms of AMS showed a slight decrease in AMS score with $\mathrm{L}$-arginine.

The decreased L-citrulline suggests a hypoxia-induced impairment of nitric oxide synthase III or a decrease in L-arginine availability. The improvement of arterial oxygen saturation by pretreatment with L-arginine could be ascribed to an enhancement of the ventilation/perfusion ratio. Collectively, these results are consistent with a decrease in nitric oxide production in hypoxia that could be antagonized by supplying nitric oxide synthase cosubstrate.

Eur Respir J 2001; 18: 286-292.
*Association pour la Recherche en Physiologie de 1'Environnement, UFR Médecine, 93017 Bobigny, France, ${ }^{\#}$ UFR Médecine Necker, 75014 Paris, France.

Correspondence: J-P. Richalet

ARPE UFR Médecine

74 , rue M. Cachin

93017 Bobigny cedex

France

Fax: 33148387777

Keywords: Cyclic guanosine 3',5'monophosphate

hypoxia

L-citrulline

nitric oxide

Received: August 182000

Accepted after revision March 262001
Exposure to high altitude causes hypoxaemia, which is often accompanied by the clinical manifestations of acute mountain sickness (AMS) and may lead to the development of pulmonary hypertension and high altitude pulmonary oedema (HAPE). Several factors are incriminated: hypoxic pulmonary vasoconstriction (HPV), water retention, and permeability alterations [1]. Increased release of vasoconstrictors, such as endothelin or catecholamines, at high altitude may be partially responsible for HPV [2]. However, impairment of nitric oxide (NO) synthesis by pulmonary endothelial cells occurs in the pulmonary hypertensive process suggesting that the increase in pulmonary vascular tone could have its origin in a decline of endothelium-dependent relaxation [3]. NO is synthesized in pulmonary artery endothelial cells by the action of the endothelial constitutive NO synthase isoform (NOS III) on the cationic amino acid $\mathrm{L}$-arginine (Arg). NO is produced from the terminal guanidino-nitrogen of Arg upon conversion to L-citrulline by NOS III in a reaction that requires molecular oxygen and cofactors. Direct measurement of NO release from vascular endothelial cells needs an
NO-selective electrode. However, L-citrulline that is formed stochiometrically with $\mathrm{NO}$ could be more easily measured than the short-lived NO. LAGERWERF et al. [4] have previously shown that determination of L-citrulline enrichments in plasma was a useful tool for assessment of in vivo NO production. Therefore, the release of $\mathrm{NO}$ can be measured directly by the L-citrulline concentration as an index of NO synthesis. Synthesis of NO by NOS depends on the availability of its substrate [5, 6]. In normal vessels, the amount of substrate is sufficient for the conversion to $\mathrm{NO}$ at a maximal rate. However, addition of Arg causes an endothelium-dependent relaxation in pulmonary arteries depleted from Arg [7]. Chronic hypoxia may impair the uptake of Arg into endothelium or alter its availability or metabolism. However, Arg deficiency does not appear to account for the decrease in NO production reported in endothelial cells exposed to short-term hypoxia [8, 9]. By contrast, Arg restores endothelium-dependent relaxation in pulmonary circulation of chronically hypoxic rats [10], suggesting that the availability of intracellular Arg is a critical factor in the regulation of the rate of NO synthesis in 
endothelial cells. Furthermore, in pulmonary hypertension, basal plasma level of Arg was below average [11], supporting the hypothesis that a relative deficiency of the Arg pool might contribute to the pathogenesis of pulmonary hypertension. Thus, understanding the metabolism of intracellular Arg might clarify the mechanism by which NO formation decreases in hypoxia. Alternatively, low oxygen tension inhibits NOS activity in biochemical assays of the isolated NOS enzyme [12] and chronic hypoxia could interrupt the NO signalling pathway at the level of guanylyl cyclase (GC) [13]. However, chronic hypoxia induced an upregulation of NOS protein expression and activity [14]. Thus, in long-term hypoxia, the part of the Arg availability seems to be lower. To explore the hypothesis that exposure to acute hypoxia is associated with a decrease in Arg availability and to confirm whether decreased NO activity in high altitude could be restored by supplying the precursor of NO, plasma L-citrulline (L-cit) and cyclic guanosine monophosphate (cGMP) concentrations were measured in humans during infusion of Arg at sea-level (normoxia) and after $36 \mathrm{~h}$ of exposure to altitude of 4,350 $\mathrm{m}$ (hypoxia). Accordingly, the effect of exogenous Arg on arterial oxygen saturation $\left(\mathrm{Sa}_{\mathrm{a}} \mathrm{O}_{2}\right)$ and AMS score were examined.

\section{Methods}

\section{Subjects}

A total of 11 healthy subjects (eight males) volunteered for the study, after approval by the Ethics Committee of Necker hospital (Paris, France). Each subject underwent a medical examination and was fully informed about the experimental procedure. All volunteers were moderately trained, sea-level natives and without experience of HAPE. They had no history of upper respiratory tract infection for $\geqslant 4$ weeks prior to the study, were not acclimatized to altitude before the experiments and did not consume any long-term medication or caffeine before the Arg load. Their age and body weight were (mean \pm SE) $27.8 \pm 1.5 \mathrm{yrs}$ and $73.0 \pm 2.8 \mathrm{~kg}$, respectively.

\section{Study design}

All experiences were performed in two conditions: at sea-level during the first week (Bobigny hospital France, altitude: $60 \mathrm{~m}$, barometric pressure $761 \pm$ $5 \mathrm{mmHg}$ ) and 3 weeks later at a field laboratory on Mont Blanc (Observatoire Vallot, altitude: 4,350 m, barometric pressure $457 \pm 1 \mathrm{mmHg}$ ). Subjects were transported by helicopter from Chamonix (altitude: $1,035 \mathrm{~m}$ ) to $4,350 \mathrm{~m}$ in $<15 \mathrm{~min}$. The temperature in the laboratory was kept constant at $20-23^{\circ} \mathrm{C}$ during the whole study. Response to Arg infusion was determined at sea-level and $36 \mathrm{~h}$ after arriving at 4,350 m. After 1-h rest in supine position, each subject had a short plastic catheter introduced in a cubital vein $15 \mathrm{~min}$ before beginning the infusion. A single dose of Arg (L-arginine-chloride; Laboratoire Veyron et Froment, Marseille, France) was infused $\left(0.5 \mathrm{~g} \cdot \mathrm{kg}^{-1}\right)$. Arg was diluted in $250 \mathrm{~mL}$ of a $5 \%$ glucose solution and the duration of the infusion was $30 \mathrm{~min}$. Each dose was administered early in the morning before breakfast. Administration of Arg was designed as time $0(t 0)$. Arterial oxygen saturation $\left(\mathrm{Sa}_{\mathrm{a}} \mathrm{O}_{2}\right)$, heart rate (HR) and supine systolic and diastolic blood pressure (SBP and DBP, respectively) were measured by an ear pulse oximeter (Biox II, Ohmeda, Montreuil, France) and an automatic sphygmomanometer (Dinamap 1846 SX P, Critikon, Blanquefort, France). One venous blood sample was collected for the measurement of L-cit concentration and cGMP concentration prior to medication. Then 15,30 and $45 \mathrm{~min}$ after the beginning of the infusion, in resting supine position ( $t 15, t 30$ and $t 45$ respectively), $S \mathrm{a}_{2} \mathrm{O}_{2}, \mathrm{HR}$ and $\mathrm{BP}$ were measured and blood was withdrawn. Clinical assessment of AMS was performed by the same observer using the Lake Louise score at the same time as blood sampling. Four symptoms were monitored: headache, gastrointestinal upset, dizziness and asthenia. The response to each of the four items was rated with a three-point scale in which a score of 0 indicated no symptoms, 1: slight symptoms, 2: moderate symptoms and 3: severe symptoms. The AMS score is the sum of the scores for the four items [15].

\section{Chromatographic measurements of L-citrulline}

Ten millilitres of blood were sampled without venostasis for L-cit and cGMP concentration measurements in plastic tubes containing ethylenediamine tetraacetic acid (EDTA). Blood was immediately centrifuged for $20 \mathrm{~min}$ at $900 \times \mathrm{g}$ at $4^{\circ} \mathrm{C}$. Plasma was carefully removed, frozen and stored in liquid nitrogen within $30 \mathrm{~min}$ for subsequent analysis. L-cit concentration was measured by ions-exchange chromatography with ninhydrin detection adapted from the technique of SLocum and Cummings [16]. Plasma was deproteinized by precipitation with sulphosalicylic acid and centrifuged at $10,000 \times g$. The supernatant was added Beckman Li-S buffer and injected into the amino acid analyser Beckman 6300 (Beckman Instruments, Roisy, CDG, France) calibrated by analysing calibration standard of known concentration. Retention time was used for amino acid identification and integration was used for quantification.

\section{Radioimmunoassay measurements of cyclic guanosine monophosphate}

NO stimulates guanylyl cyclase to produce cGMP, an intermediate in the endothelium-dependent relaxation of blood vessel. To study the NO-cGMP pathway, cGMP concentration was measured by immunoassay. The nuclear radioimmunoassay kit for the determination of cGMP is adapted from the procedures of STEINER et al. [17]. Increase in sensitivity was achieved by succinylating samples with succinic anhydride, then the tracer was added and incubated for $22 \mathrm{~h}$ at $4{ }^{\circ} \mathrm{C}$ (kit Beckman-Coulter, Immunotech 


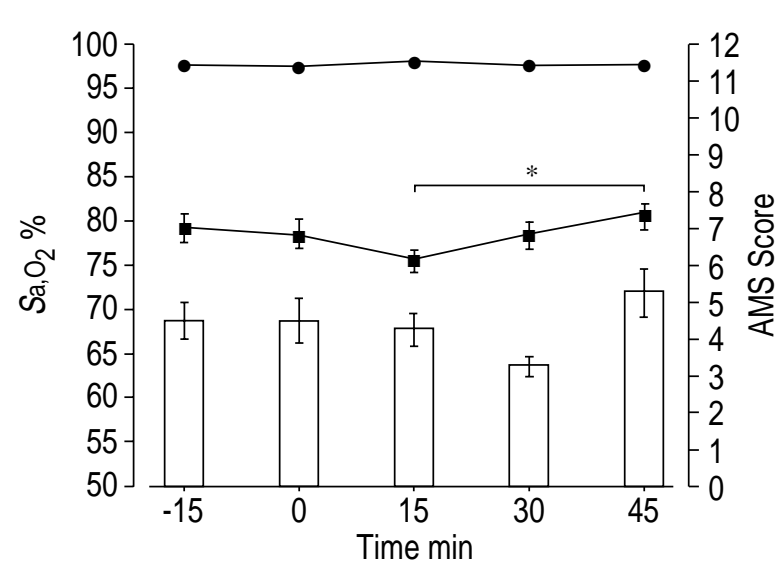

Fig. 1.-Arterial oxygen saturation $\left(\mathrm{S}_{\mathrm{a}}, \mathrm{O}_{2}\right)$ and acute mountain sickness score (AMS score; $\square$ ) during L-arginine infusion at sealevel (O) and after $36 \mathrm{~h}$ of exposure to altitude of $4,350 \mathrm{~m}(\boldsymbol{\square})$. Values are mean $\pm \mathrm{SE} ; \mathrm{n}=11$. L-arginine infusion $\left(0.5 \mathrm{~g} \cdot \mathrm{kg}^{-1}\right.$ in $30 \mathrm{~min}$ ) occurred after $15 \mathrm{~min}$ of rest in supine position and was followed by $15 \mathrm{~min}$ of recovery. $*$ : $\mathrm{p}<0.05$, significantly different from $15 \mathrm{~min}$ after the beginning of the infusion $(t 15)$.

SA, Marseille, France). Radioimmunoassays of cyclic nucleotides (e.g. cGMP) in biological fluids currently involve the use of specific antibodies and ${ }^{125} \mathrm{I}$-labelled tracers. Femtomole levels could be measured when ${ }^{125} \mathrm{I}$-labelled tracers and $2^{\prime}$-O-derivatization procedures are used.

\section{Statistical analysis}

All data are expressed as means \pm SE. A two-way analysis of variance with repeated measures was performed to make comparisons between altitude conditions and across time for clinical data, $\mathrm{Sa}, \mathrm{O}_{2}$, cardiovascular data and blood sample. If the F-value indicated significant differences among group means, the overall significance of the variation with time including conditions normoxia and hypoxia were assessed using a paired t-test. Linear regressions were performed by using the least squares method. A p-value $<0.05$ was considered as significant.

\section{Results}

\section{Clinical data}

Only four subjects experienced symptoms of AMS at Observatoire Vallot (score $>2$ ). Variations of AMS score are shown in figure 1. Subjects who experienced symptoms of AMS showed a slightly decreased AMS score with Arg infusion, mean minimal score was observed at the end of Arg infusion but no significant correlation was found. Fifteen minutes after the end of the infusion, the AMS score retrieved its baseline level, whereas $\mathrm{Sa}_{\mathrm{a}} \mathrm{O}_{2}$ stayed higher. In the present study, the experiments were performed in the morning, which corresponds to the period of maximal AMS symptoms during the daytime [18]. The most frequent symptom was headache. No subject experienced clinical signs of pulmonary or cerebral oedema.

\section{Physical data}

$\mathrm{Sa}, \mathrm{O}_{2}$ decreased by $20 \pm 2 \%$ from sea-level to $4,350 \mathrm{~m}$ (fig. 1). In normoxia, $\mathrm{Sa}_{2} \mathrm{O}_{2}$ was not modified by Arg infusion. In hypoxia, $\mathrm{Sa}, \mathrm{O}_{2}$ tended to decrease before and in the first $15 \mathrm{~min}$ of Arg infusion, and then increased from 15-45 min. $S \mathrm{a}_{2} \mathrm{O}_{2}$ was higher by $3.2 \pm 0.4 \%$ from $t 15$ to $t 30$ and by $5.3 \pm 0.3 \%$ from $t 15$ to $t 45(\mathrm{p}<0.05)$. This increase was parallel to $\mathrm{L}$-cit concentration but no significant correlation was found. SBP and DBP remained unchanged at 4,350 $\mathrm{m}$ (table 1). In both conditions, SBP and DBP did not vary during Arg infusion. HR increased by $25 \pm 1 \%(\mathrm{p}<0.01)$ from sea-level to $4,350 \mathrm{~m}$ (table 1$)$. HR did not vary during Arg infusion in both conditions.

\section{Venous plasma}

L-cit and cGMP concentration are shown in figures 2 and 3 respectively. Baseline L-cit concentration decreased from $33.1 \pm 1.7 \mu \mathrm{M} \cdot \mathrm{L}^{-1}$ at sea-level to $28.5 \pm 2.1 \mu \mathrm{M} \cdot \mathrm{L}^{-1}$ at $4,350 \mathrm{~m}(\mathrm{p}<0.05)$. In both conditions, L-cit concentration increases during Arg

Table 1. - Systolic (SBP) and diastolic (DBP) blood pressure and heart rate (HR) during L-arginine infusion at sea-level and after $36 \mathrm{~h}$ of exposure to altitude of $4,350 \mathrm{~m}$

\begin{tabular}{|c|c|c|c|c|c|}
\hline \multirow[t]{2}{*}{ Variables } & \multirow[t]{2}{*}{ Rest } & \multicolumn{3}{|c|}{ L-arginine infusion } & \multirow{2}{*}{$\begin{array}{c}\text { Recovery } \\
45 \text { min }\end{array}$} \\
\hline & & Baseline & $15 \mathrm{~min}$ & $30 \mathrm{~min}$ & \\
\hline \multicolumn{6}{|l|}{ SBP mmHg } \\
\hline Normoxia & $116.8 \pm 4.3$ & $117.4 \pm 3.4$ & $119.0 \pm 5.1$ & $116.8 \pm 3.4$ & $117.9 \pm 3.7$ \\
\hline $\begin{array}{l}\text { Hypoxia } \\
\text { DBP } \mathrm{mmHg}\end{array}$ & $117.6 \pm 3.8$ & $119.6 \pm 2.6$ & $116.7 \pm 3.6$ & $115.1 \pm 3$ & $116.7 \pm 3.5$ \\
\hline Normoxia & $70.0 \pm 2.6$ & $69.9 \pm 2.6$ & $71.4 \pm 4.3$ & $68.1 \pm 3.9$ & $70.2 \pm 4$ \\
\hline $\begin{array}{l}\text { Hypoxia } \\
\text { HR bpm }\end{array}$ & $73.6 \pm 3.3$ & $72.3 \pm 3.2$ & $71.9 \pm 3.1$ & $70.2 \pm 2.3$ & $68.6 \pm 3.9$ \\
\hline Normoxia & $62 \pm 2.9$ & $61.9 \pm 2.9$ & $62.2 \pm 3$ & $59.8 \pm 2.3$ & $59.8 \pm 2.6$ \\
\hline Hypoxia & $75.2 \pm 3.5^{* *}$ & $75.1 \pm 3.5^{* *}$ & $76.0 \pm 3.8^{* *}$ & $77.5 \pm 3.8^{* *}$ & $75.7 \pm 3.8^{* *}$ \\
\hline
\end{tabular}

Values are mean $\pm \mathrm{SE} ; \mathrm{n}=11$. L-arginine infusion $\left(0.5 \mathrm{~g} \cdot \mathrm{kg}^{-1}\right.$ in $\left.30 \mathrm{~min}\right)$ occurred after $15 \mathrm{~min}$ of rest in supine position and was followed by $15 \mathrm{~min}$ of recovery. bpm: beats per minute. ${ }^{* *}: \mathrm{p}<0.01$ compared to normoxia. 


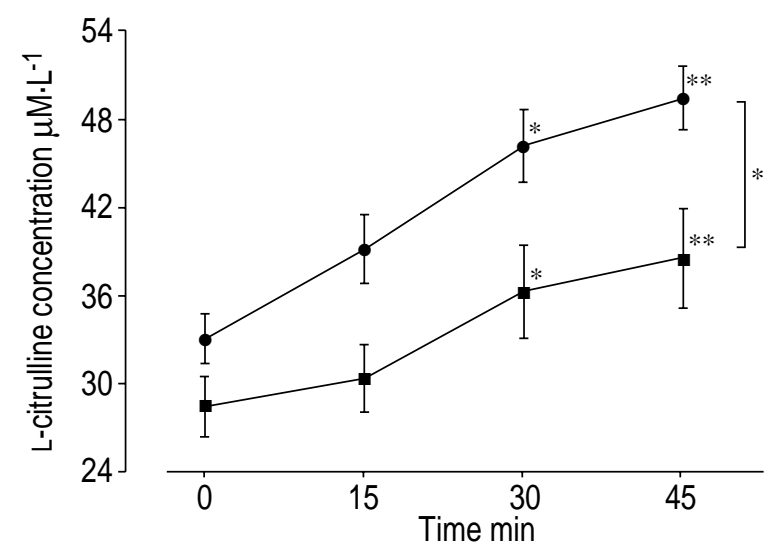

Fig. 2.-L-citrulline plasma concentration during L-arginine infusion at sea-level (O) and after $36 \mathrm{~h}$ of exposure to altitude of $4,350 \mathrm{~m}$ (ם). Values are means $\pm \mathrm{SE} ; \mathrm{n}=11$. L-arginine infusion $\left(0.5 \mathrm{~g} \cdot \mathrm{kg}^{-1}\right.$ in $\left.30 \mathrm{~min}\right)$ occurred after $15 \mathrm{~min}$ of rest in supine position and was followed by $15 \mathrm{~min}$ of recovery. $*$ : $\mathrm{p}<0.05$; **: $\mathrm{p}<0.01$, significantly different from baseline in normoxia or hypoxia.

infusion from respective baseline to $46.2 \pm 2.5 \mu \mathrm{M} \cdot \mathrm{L}^{-1}$ at sea-level and $36.3 \pm 3.2 \mu \mathrm{M} \cdot \mathrm{L}^{-1}$ at $4,350 \mathrm{~m}(\mathrm{p}<0.05)$. Moreover, concentration remained higher after $15 \mathrm{~min}$ recovery $(t 45)$. Therefore, L-cit concentration increased by $49 \pm 1 \%$ at sea-level and $35 \pm 2 \%$ at $4,350 \mathrm{~m}$ from to to $t 45(\mathrm{p}<0.01)$. However, $\mathrm{L}$-cit concentration in hypoxia remained below the normoxia value by $22 \pm 1 \%$ throughout Arg infusion and recovery $(\mathrm{p}<0.05)$. cGMP concentration was lower at $4,350 \mathrm{~m}$ than at sea level $(\mathrm{p}<0.05)$. In normoxia, cGMP concentration increased from $2.8 \pm 0.5 \mathrm{nM}^{-1}$ at $t 0$ to $4.2 \pm 0.6 \mathrm{nM} \cdot \mathrm{L}^{-1}$ at $t 45(53 \pm 6 \%, \mathrm{p}<0.05)$. Moreover, cGMP concentration increase was positively correlated to $\mathrm{L}$-cit concentration increase $(\mathrm{r}=0.96, \mathrm{p}<0.05)$ (fig. 4). In hypoxia the concentration of cGMP remained unchanged during Arg infusion and the correlation was not significant.

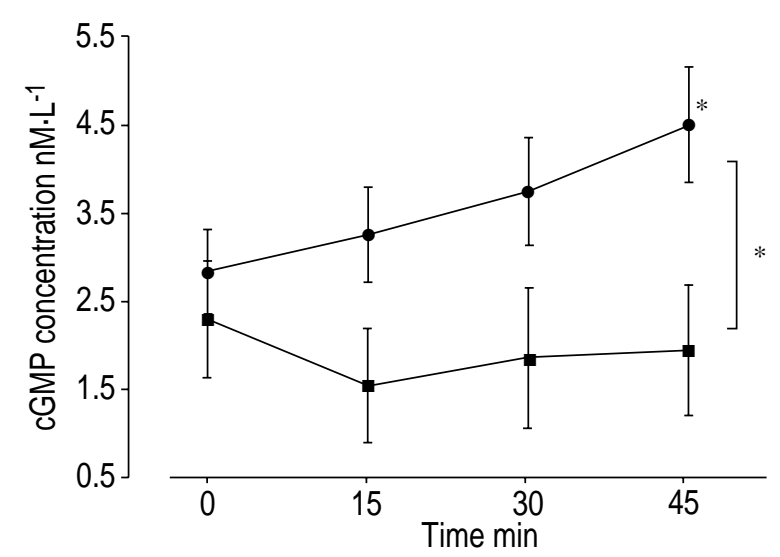

Fig. 3.-Cyclic guanosine $3^{\prime}, 5^{\prime}$-monophosphate (cGMP) plasma concentration during L-arginine infusion at sea level $(\bullet)$ and after $36 \mathrm{~h}$ of exposure to altitude of $4,350 \mathrm{~m}(\boldsymbol{\square})$. Values are means \pm $\mathrm{SE}$; $\mathrm{n}=10$. L-arginine infusion $\left(0.5 \mathrm{~g} \cdot \mathrm{kg}^{-1}\right.$ in $\left.30 \mathrm{~min}\right)$ occurred after $15 \mathrm{~min}$ of rest in supine position and was followed by $15 \mathrm{~min}$ of recovery. ${ }^{*}: \mathrm{p}<0.05$.

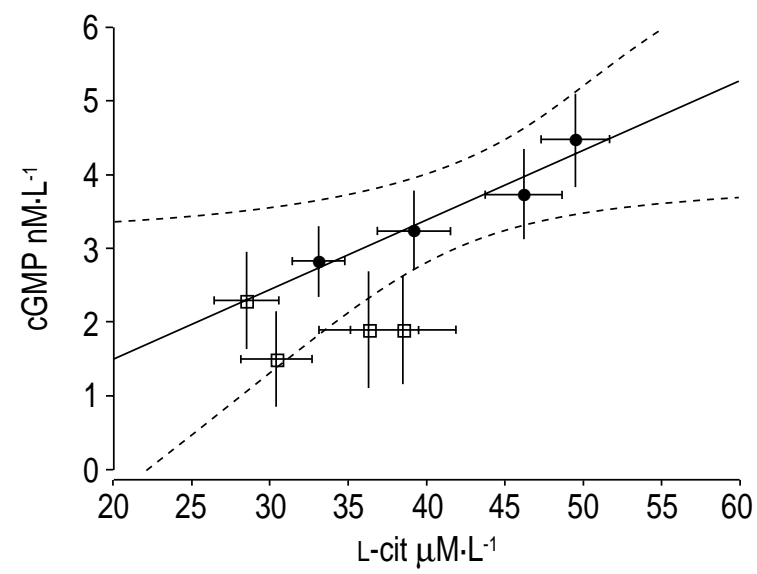

Fig. 4.-Relationship between L-citrulline (L-cit) and cyclic guanosine monophosphate (cGMP) concentration in 10 subjects during L-arginine infusion at sea-level (O) and after $36 \mathrm{~h}$ of exposure to altitude of $4,350 \mathrm{~m}(\square)$. The regression equation is [cGMP]= 0.09 [L-cit] $-0.38, \mathrm{r}=0.96(\mathrm{p}<0.05)$ at sea-level, where [cGMP] is cGMP concentration and [L-cit] is L-cit concentration, no correlation was found at $4,350 \mathrm{~m}$.

\section{Discussion}

The presented results showed that $36 \mathrm{~h}$ of exposure to altitude of $4,350 \mathrm{~m}$, decreased plasma L-cit and cGMP concentrations. Arg infusion increased L-cit concentrations in normoxia and hypoxia, whereas Arg infusion only increased cGMP in normoxia. In addition, Arg infusion tended to increase $\mathrm{Sa}_{\mathrm{a}} \mathrm{O}_{2}$ without systemic effects at high altitude.

\section{L-arginine availability}

The availability of intracellular Arg is a critical factor in the regulation of the rate of NO synthesis in endothelial cells. The Arg content of endothelial cells is derived primarily from plasma membranedependent transport of extracellular Arg, but can also be synthesized from L-cit [19]. BLOCK et al. [20] showed that exposure to hypoxia causes significant reduction in the transport of Arg, only accompanied by a decrease in intracellular Arg content after long-term exposure to hypoxia. Su and BLock [21] demonstrated that hypoxia time dependently inhibits the synthesis of Arg from L-cit in pulmonary artery endothelial cells. These results suggest that hypoxia-induced L-cit concentration decrease might not be due to the capacity of endothelial cell to recycle L-cit and since the Arg-NO pathway represents the major metabolic pathway, it can be assumed that decreased L-cit was caused by an effect of hypoxia on Arg metabolism. However, NO production is linked to the rate of transformation of Arg to L-cit, which depends on cardiac blood flow and arteriovenous difference. In acute hypoxia, cardiac blood flow increases and L-cit concentration decreases suggesting that NO production might not be correlated to L-cit concentration. Although, hypoxia resulted in a decrease in the conversion of L-cit, intracellular Arg content was increased in the hypoxic pulmonary artery endothelial cells $[22,23]$. Thus, lack of availability of intracellular 
Arg does not appear to account for the decrease in NO production unless the intracellular pools of Arg are inaccessible to NOS III in hypoxia. This is of particular relevance to endothelium because NOS III is membrane-associated and thus, a membranerelated pool of Arg may be critical to the activity of the enzyme. In normal vessels, the amount of the substrate is sufficient for conversion to $\mathrm{NO}$ at a maximal rate. However, addition of Arg causes an endothelium-dependent relaxation in pulmonary artery depleted of Arg [7]. Administration of substrate for NOS restores endothelium-dependent vasodilatory response in hypoxia-induced pulmonary hypertension $[10,24]$. In patients with pulmonary hypertension, Arg reduced the pulmonary vascular resistance and the magnitude of the pulmonary vasodilatory response was correlated to the level of L-cit [11]. Furthermore, although NOS expression was upregulated in the early course of development of HPV [25], NOS activity was not increased if the substrate for the NOS enzyme was limiting $[26,27]$. Thus, the increase in L-cit and the short-term oxygenation effect of exogenous Arg at high altitude may be due to enhanced NO production in the pulmonary vasculature, and increase in Arg availability can promote L-cit/NO synthesis in high altitude. The vascular effect of Arg may be mediated through NO-independent mechanisms such as the effect of $\mathrm{pH}$. Although alkaline solutions of Arg can induce vasodilatation, Arg hydrochloride solution was slightly acidic, weakening an effect of the $\mathrm{pH}$. As Arg was infused with glucose, the direct effect of carbohydrates on ventilation/perfusion ratio should not be ruled out. However, this effect could be NOindependent since hyperglycaemia did not affect endothelium-dependent vasoreactivity in humans [28]. Alternatively, a nutritional deficiency might not have contributed to the concentration decrease of L-cit during $36 \mathrm{~h}$ of hypoxia and Arg availability is low owing to extensive protein binding.

\section{Ventilation/perfusion ratio}

PIsON [29] demonstrated that NO may improve ventilation and perfusion matching, as well as excretion and retention dispersion indexes, suggesting an improvement in gas exchange because of a redistribution of both ventilation and blood flow. In HAPE, inhalation of NO redistributed blood flow in the lungs away from oedematous regions, which improved the matching of ventilation and perfusion and reducing the alveolar-arterial oxygen difference [30]. Thus, the improvement of the $\mathrm{Sa}_{\mathrm{a}} \mathrm{O}_{2}$ with $\mathrm{Arg}$ suggests that the NO substrate could be a useful adjuvant in the treatment of high altitude pulmonary hypertension, which is implicated in the pathogenesis of HAPE. Alternatively, NO induces vasodilatation of bronchial artery in both normoxia and hypoxia [31] and modulates agonist-induced bronchoconstriction [32]. The improvement of $\mathrm{Sa}_{\mathrm{a}} \mathrm{O}_{2}$ may be due to the vasodilatory effect of $\mathrm{NO}$ on the small vascular pulmonary arteries thereby increasing the perfusion/ ventilation ratio. However, Arg-induced hyperventilation might not be ruled out. Furthermore, as subjects prone to HAPE have a less compliant pulmonary circulation due to multifactorial mechanism, including reduced NO synthesis [33], Arg infusion may prevent, at least in part, the complication of HPV. The initial decrease in the $\mathrm{Sa}_{\mathrm{a}} \mathrm{O}_{2}$ may be due to reclined position during the procedure, since lying flat in bed raises intrathoracic blood volume and consequently, pulmonary arterial pressure [18].

\section{Guanylyl cyclase}

In bovine arterial rings, a depletion of tissue Arg is associated with a decrease in basal cGMP levels and impairment of endothelium-dependent cGMP formation [7]. However, basal guanylyl cyclase activity did not differ significantly between normoxic and hypoxic lungs [25]. The decreased cGMP at 4,350 $\mathrm{m}$ assumes that Arg content was lower at $4,350 \mathrm{~m}$. However, in hypoxia no correlation was found between L-cit and cGMP concentration variation, suggesting that the cGMP metabolism differs from sea-level to $36 \mathrm{~h}$ of exposure to altitude of $4,350 \mathrm{~m}$. Conversely, the nonspecificity of the plasma cGMP level may explain the discrepancy of these results in hypoxia.

\section{Systemic vessel}

Administration of Arg results in an increase in the concentration of NO in the exhaled air matched by an increase in the concentration of $\mathrm{NO}_{3}{ }^{-}$in the plasma [34]. Bode-BögER et al. [35] showed that Arg induced vasodilatation in healthy humans in normoxia and BLITZER et al. [36] demonstrated that NOS inhibition increased systemic vascular resistance and BP and decreased cardiac output in short-term hypoxia. However, the presented results show that Arg infusion was not associated with any measurable change in systemic haemodynamics, suggesting the absence of a direct effect of NOS substrate on heart and vascular smooth muscle of the systemic vessels. The discrepancy of the findings may be explained by the baseline level of SBP and DBP (150/90 for BODE-BögER et al. [35] and 120/70 for the present study) and by inactivation of free NO by high-affinity binding to haemoglobin in hypoxia. Furthermore, in the protocol of BLITZER et al. [36], decrease in the fraction of inspired oxygen was induced by breathing hypoxic mixture and the duration of hypoxia was less than the present study.

\section{Conclusion}

In the present study, L-arginine infusion at doses avoiding systemic haemodynamic effects have allowed for the improvement of arterial oxygen saturation at $4,350 \mathrm{~m}$ after intravenous administration of a nitric oxide synthetase substrate used as a surrogate for directional changes in nitric oxide pathway. This effect may be due to the confounding effects of changes in flow through the pulmonary circulation and ventilation from increase in nitric oxide activity. Potential mechanisms to explain the decrease of 
L-citrulline at 4,350 m include: 1) impairment of the nitric oxide synthase activity in high altitude; 2) decrease of the nitric oxide substrate bioavailability; and 3) enhancement of the catabolism of L-citrulline. However, the improvement during L-arginine infusion suggests that L-arginine could preserve endothelial function and obviate the pathological consequences of hypoxia.

Acknowledgements. The authors are indebted to A. Tuan Dinh-Xuan for editorial comments.

\section{References}

1. Richalet J-P. High altitude pulmonary edema: still a place for controversy. Thorax 1995; 50: 923-929.

2. Richalet J-P, Hornych A, Rathat C, Aumont J, Larmignat P, Remy P. Plasma prostaglandins, leukotrienes and thromboxane in acute high altitude hypoxia. Respiration Physiol 1991; 85: 205-215.

3. Dinh-Xuan AT, Higgembottam TW, Clelland C, et al. Impairment of endothelium-dependent pulmonary artery relaxation in chronic obstructive lung disease. N Engl J Med 1991; 324: 1539-1547.

4. Lagerwerf FM, Wever RM, van Rijn $\mathrm{HJ}$, et al. Assessment of nitric oxide production by measurement of $[15 \mathrm{~N}]$ citrulline enrichment in human plasma using high-performance liquid chromatography-mass spectrometry. Anal Biochem 1998; 257: 45-52.

5. Palmer RMJ, Ashton DS, Moncada S. Vascular endothelial cells synthesize nitric oxide from L-arginine. Nature 1988; 333: 664-666.

6. Palmer RMJ, Moncada S. A novel citrulline-forming enzyme implicated in the formation of nitric oxide by vascular endothelial cells. Biochem Biophys Res Commun 1989; 158: 348-352.

7. Gold ME, Wood KS, Byrns RE, Buga GM, Ignarro LJ. L-arginine-dependent vascular smooth muscle relaxation and cGMP formation. Am J Physiol 1990; 259: H1813-H1851.

8. Shaul PW, Wells LB, Horning KM. Acute and prolonged hypoxia attenuate endothelial nitric oxide production in rat pulmonary arteries by different mechanisms. J Cardiovasc Pharmacol 1994; 22: 819827.

9. Warren JB, Maltby NH, MacCormack D, Barnes PJ. Pulmonary endothelium-derived relaxing factor is impaired in hypoxia. Clin Sci 1989; 77: 671-676.

10. Eddahibi S, Adnot S, Carville C, Blouquit Y, Raffestin B. L-arginine restores endothelium-dependent relaxation in pulmonary circulation of chronically hypoxic rats. Am J Physiol 1992; 263: L194L200.

11. Mehta S, Stewart DJ, Langleben D, Levy RD. Shortterm pulmonary vasodilation with $\mathrm{L}$-arginine in pulmonary hypertension. Circ 1995; 92: 1539-1545.

12. Rengasamy A, Johns RA. Characterization of endothelium-derived relaxing factor/nitric oxide synthase from bovine cerebellum and mechanism of modulation by high and low oxygen tensions. J Pharmacol Exp Ther 1991; 259: 301-316.

13. Crawley DE, Zhao L, Giembycz MA, et al. Chronic hypoxia impairs soluble guanylyl cyclase-mediated pulmonary arterial relaxation in the rat. Am J Physiol 1992; 263: L325-L332.

14. Xue C, Rengasamy A, Le Cras TD, Koberna PA, Dailey GC, Johns RA. Distribution of NOS in normoxic vs. hypoxic rat lung: upregulation of NOS by chronic hypoxia. Am J Physiol 1994; 267: L667L678.

15. Hackett $\mathrm{P}$. The Lake Louise consensus on the definition and quantification of the altitude illness. In: Sutton JR, Coates G, Houston CS. Hypoxia and mountain. Burlington, USA, Queen city printers Inc., 1992; pp. 327-330.

16. Slocum RH, Cummings JG. Amino acid analysis of physiological samples. In: FA Hommes, ed. Techniques in diagnosis human biochemical genetics, a laboratory manual. New York, Wiley-Liss, 1991; pp. 87-126.

17. Steiner AL, Pagliara AS, Chase LR, Kipnis DM. Radioimmunoassay for cyclic nucleotides. II. Adenosine 3',5'-monophosphate and guanosine 3',5'-monophosphate in mammalian tissues and body fluids. J Biol Chem 1972; 247: 1114-1120.

18. Richalet J-P, Rutgers V, Bouchet $\mathrm{P}$, et al. Diurnal variations of acute mountain sickness, colour vision, and plasma cortisol and ACTH at high altitude. Aviat Space Environ Med 1989; 60: 105-111.

19. $\mathrm{Wu} \mathrm{G}$, Meininger CJ. Regulation of L-arginine synthesis from L-citrulline by L-glutamine in endothelial cells. Am J Physiol 1993; 263: H1965-H1971.

20. Block ER, Herrera H, Couch M. Hypoxia inhibits L-arginine uptake by pulmonary artery endothelial cells. Am J Physiol 1995; 269: L574-L580.

21. Su Y, Block ER. Hypoxia inhibits L-arginine synthesis from L-citrulline in porcine pulmonary artery endothelial cells. Am J Physiol 1995; 269: L581-L587.

22. Hecker M, Sessa WC, Harris HJ, Hangaard EE, Vane JR. The metabolism of L-arginine and its significance for the biosynthesis of endothelium-derived relaxing factor: cultured endothelial cells recycle L-citrulline to arginine. Proc Natl Acad Sci USA 1990; 87: 86128616.

23. Su Y, Block ER. Acute hypoxia increases intracellular L-arginine content in cultured porcine pulmonary artery endothelial cells. $J$ Cell Physiol 1996; 167: 349-353.

24. Adnot S, Raffestin B, Eddahibi S, Braquet P, Chabrier $\mathrm{PE}$. Loss of endothelium-dependent relaxant activity in the pulmonary circulation of rats exposed to chronic hypoxia. J Clin Invest 1991; 87: 155-162.

25. Xue C, Roger AJ. Upregulation of nitric oxide synthase correlates temporally with onset of pulmonary vascular remodeling in the hypoxic rat. Hypertension 1996; 28: 743-753.

26. Shaul PW, North AJ, Brannon TS, et al. Prolonged in vivo hypoxia enhances nitric oxide synthase type I and type III gene expression in adult rat lung. Am J Respir Cell Mol Biol 1995; 13: 167-174.

27. Le Cras TD, Xue C, Rengasamy A, Roger AJ. Chronic hypoxia upregulates endothelial and inducible NO synthase gene and protein expression in rat lung. Am J Physiol 1996; 270: L164-L170.

28. Houben AJ, Schaper NC, de Haan $\mathrm{CH}$, et al. Local 24-h hyperglycemia does not affect endotheliumdependent or -independent vasoreactivity in humans. Am J Physiol 1996; 270: H2014-H2020.

29. Pison U. Inhaled nitric oxide reverses hypoxic 
pulmonary vasoconstriction without impairing gas exchange. J Appl Physiol 1993; 74: 1287-1292.

30. Scherrer U, Vollenweider L, Delabays A, et al. Inhaled nitric oxide for high-altitude pulmonary edema. $N$ Engl J Med 1996; 334: 624-629.

31. Frostell CG, Blomqvist H, Hedenstierna G, Lundberg J, Zapol WM. Inhaled nitric oxide selectively reverses human hypoxic pulmonary vasoconstriction without causing systemic vasodilation. Anesthesiol 1993; 78: 427-435.

32. Hogman M, Frostell CG, Hedenstrom H, Hedenstierna G. Inhalation of nitric oxide modulates adult human bronchial tone. Am Rev Respir Dis 1993; 148: 1474 1478.
33. Gibbs JS. Pulmonary hemodynamics: implications for high altitude pulmonary edema (HAPE). $A d v$ Exp Med Biol 1999; 474: 81-91.

34. Kharitonov SA, Lubec G, Lubec B, Hjelm M, Barnes PJ. L-arginine increases exhaled nitric oxide in normal human subjects. Clin Sci 1995; 88: 135-139.

35. Bode-Böger SM, Böger RH, Galland A, Tsikas D, Frölich JC. L-arginine-induced vasodilatation in healthy humans: pharmacokinetic-pharmacodynamic relationship. Br J Clin Pharmacol 1998; 46: 489-497.

36. Blitzer ML, Loh E, Roddy MA, Stamler JS, Creager MA. Endothelium-derived nitric oxide regulates systemic and pulmonary vascular resistance during acute hypoxia in humans. J Am Coll Cardiol 1996; 28: 591-596. 